\title{
São Paulo Centro - 150 anos de projetos e realizações: estudos sobre as dinâmicas de evolução de seus espaços públicos
}

\author{
City Center São Paulo - 150 years of Projects and \\ achievements: studies on the evolution dynamics of its \\ public spaces
}

\section{São Paulo Centro - 150 años de proyectos y logros: estudio sobre las dinámicas de evolución de sus espacios públicos}

Andre Soares Haidar, Mestre em Arquitetura e Urbanismo pelo Programa de Pós-Graduação Stricto Sensu em Arquitetura e Urbanismo da Universidade Presbiteriana Mackenzie. E-mail: as.haidar@hotmail.com (iD)ORCID: https://orcid.org/0000-0001-6751-0193

Para citar este artigo: HAIDAR, A. S. São Paulo Centro - 150 anos de projetos e realizações: estudos sobre as dinâmicas de evolução de seus espaços públicos. Cadernos de Pós-Graduação em Arquitetura e Urbanismo, São Paulo, v. 22, n.1, p.136150, 2022. DOI 10.5935/cadernospos.v22n1p136-150

Submissão: 2021-04-10

Aceite: $2021-09-20$

\section{Resumo}

Este artigo surge como fruto de uma Dissertação de Mestrado desenvolvida no Programa de Pós-Graduação em Arquitetura e Urbanismo da Universidade Presbiteriana Mackenzie, apresentando como questão central a investigação sobre os espaços públicos do centro da 
cidade de São Paulo, com suas diferentes vertentes e sua evolução, através de distintas proposições e projetos, ao longo do tempo. Tomando-se como ponto de partida a construção de uma linha do tempo, foi feita a divisão do recorte temporal em períodos distintos, através da busca por características comuns nos métodos de abordagem das propostas em relação ao espaço público da cidade. As divisões temporais permitem a exploração de aspectos comuns nas abordagens das administrações públicas, em relação aos espaços centrais da cidade, ao mesmo tempo que facilitam a compreensão do conjunto de elementos que caracterizam aquele espaço (o Centro) ao longo dos anos. Utilizando-se de uma metodologia historiográfica, através da organização de dados coletados por meio de fontes primárias e secundárias, pretende-se destacar alguns projetos específicos representativos das distintas divisões adotadas no trabalho, para um estudo capaz de encontrar características universalizantes, passíveis de explicar as estruturas funcionais e econômicas mais amplas por trás das intervenções no Centro.

Palavras-chave: Espaço público; Evolução urbana; Políticas públicas urbanas; Intervenção Urbana.

\begin{abstract}
This article was written as the result of a Master's Dissertation developed in the Graduate Program in Architecture and Urbanism at Universidade Presbiteriana Mackenzie, presenting as a central question the investigation of public spaces in the center of the city of São Paulo, with its different aspects and its evolution, through different propositions and projects, over time. Taking the construction of a timeline as a starting point, the time frame was divided into distinct periods, through the search for common characteristics in the methods of approaching the proposals in relation to the public space of the city. The temporal divisions allow the exploration of common aspects in the approaches of public administrations, in relation to the central spaces of the city, while facilitating the understanding of the set of elements that characterize that space (the City Center) over the years. Using a historiographic methodology, through the organization of data collected from primary and secondary sources, it is intended to highlight some specific projects representative of the different divisions adopted in the work, for a study capable of finding universalizing characteristics, capable of explaining the broader functional and economic structures behind interventions at the Center.
\end{abstract}

Keywords: Public place; Urban Evolution; Urban public policies; Urban intervention.

\title{
Resumen
}

Este artículo fue escrito como resultado de una Disertación desarrollada en el Programa de Posgrado en Arquitectura y Urbanismo de la Universidade Presbiteriana Mackenzie, presentando como pregunta central la investigación de los espacios públicos en el centro de la ciudad de São Paulo, con sus diferentes aspectos y su evolución, a través de diferentes propuestas y proyectos, a lo largo del tiempo. Tomando como punto de partida la construcción de una línea de tiempo, el marco temporal se dividió en distintos períodos, a través de la búsqueda de características comunes en los métodos de abordaje de las 
propuestas en relación al espacio público de la ciudad. Las divisiones temporales permiten explorar aspectos comunes en los planteamientos de las administraciones públicas, en relación con los espacios centrales de la ciudad, al tiempo que facilitan la comprensión del conjunto de elementos que caracterizan ese espacio (el Centro de la Ciudad) a través de los años. Utilizando una metodología historiográfica, a través de la organización de los datos recolectados de fuentes primarias y secundarias, se pretende resaltar algunos proyectos específicos representativos de las diferentes divisiones adoptadas en el trabajo, para un estudio capaz de encontrar características universalizantes, capaces de explicar los aspectos funcionales más amplios. y estructuras económicas detrás de las intervenciones en el Centro.

Palabras clave: Espacio público; Evolución urbana; Políticas Públicas urbanas; Intervención urbana.

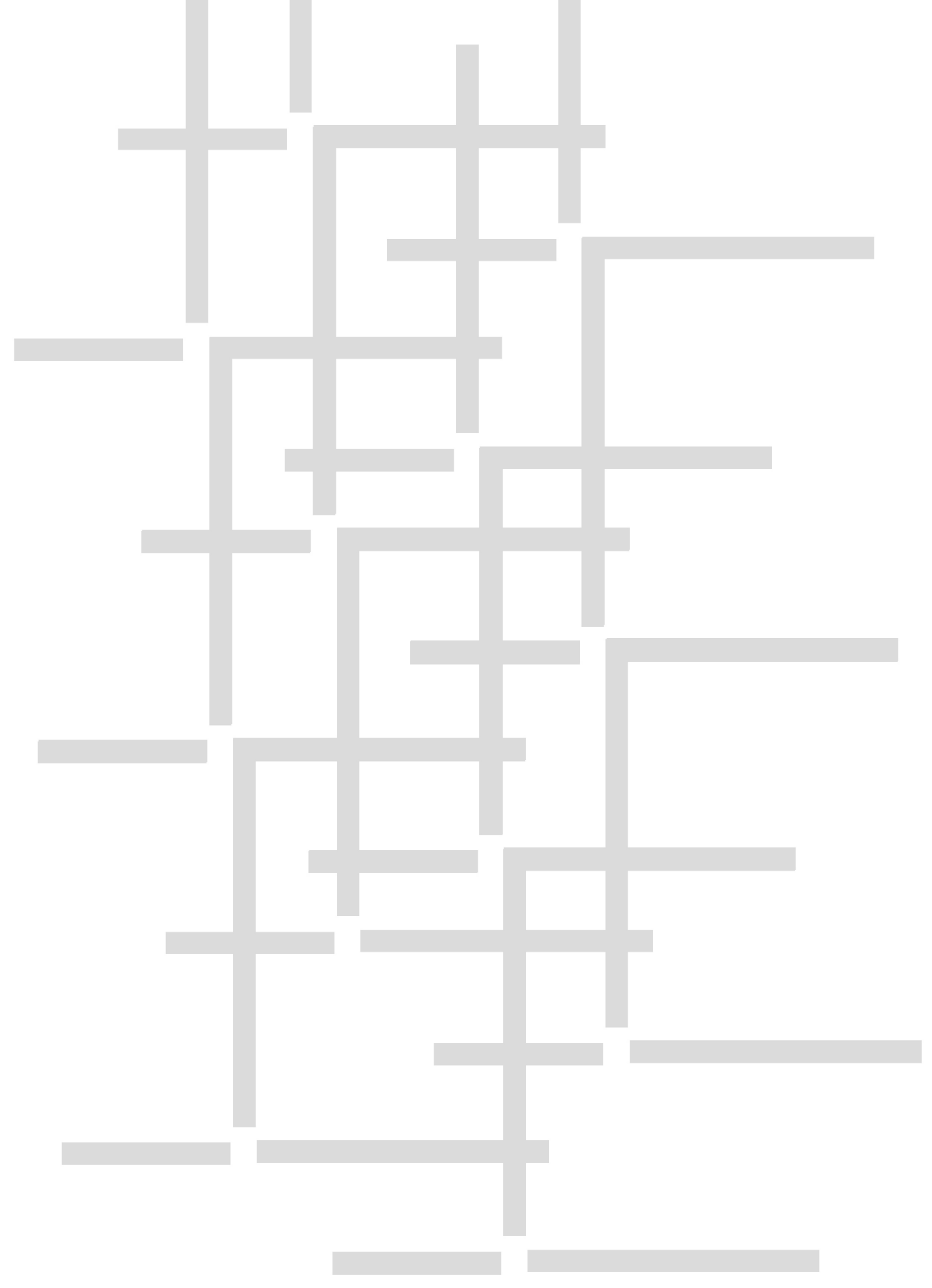




\section{INTRODUÇÃO}

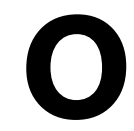

objetivo central que motiva o desenvolvimento desta pesquisa abrange a busca pela compreensão do percurso que a região central de São Paulo teve para obter a conformação que alcança à segunda década do século XXI. A partir desse objetivo surge a definição do objeto de estudo, que é o espaço público do Centro, com suas diferentes vertentes e suas transformações, tanto de seu traçado físico quanto de aspectos paisagísticos e funcionais; através de diferentes proposições e projetos, ao longo do tempo.

O objetivo específico deste trabalho não é elencar todas as propostas já feitas e executadas em relação ao Centro, mas selecionar propostas de diferentes gestões para estudo, discutindo e traçando um cenário das forças que atuam no desenho dos espaços no centro de São Paulo. Pontua-se também as forças que se manifestam nas tendências de projeto do poder público, pois este é reflexo direto da vontade e anseio de camadas da população, variando, é claro, entre os detendores do capital e meios de produção, para os movimentos e organizações da sociedade civil.

O desenvolvimento dessa investigação norteia-se por uma metodologia historiográfica acerca do percurso de estudos a ser tomado. A coleta de dados por fontes secundárias - com a pesquisa de pertinentes autores e de fontes primárias, em especial consultadas em arquivos municipais e levantamento fotográfico - foi gerenciada de modo a fazer uma divisão temporal de todo o período de estudo em específicas épocas com suas características distintas, compilando projetos adequados para cada momento. Essa seleção buscou referenciais pontuais, porém com características universalizantes, capazes de explicar as estruturas funcionais e econômicas por trás das intervenções no Centro.

O estudo deste trabalho baseou-se, traçando uma linha contínua de abordagem, em dois conceitos: espaço e Estado. O primeiro é entendido a partir dos escritos de Milton Santos (1997), nos quais o autor conceitua o espaço como um conjunto de fatores, entendidos, por um lado, como "objetos geográficos distribuídos sobre um território" (SANTOS, 1997, p. 1-2), cuja organização espacial permite a formação de uma continuidade visível, de paisagem; e, por outro, todo o conjunto de processos sociais "representativos de uma sociedade em um dado momento" (id.).

O espaço seria dedutível a diferentes elementos para análise: "os homens, as firmas, as instituições, o chamado meio ecológico e as infra-estruturas" (SANTOS, 1997, p. 05). O homem é elemento do espaço por exercer alterações por meio de suas demandas de uso e necessidades. As firmas respondem às necessidades de produção de bens, ideias e serviços, já as instituições são responsáveis pela produção de legislações, normas e ordem. O meio ecológico é o conjunto "de complexos territoriais que constituem a base física do trabalho humano" (SANTOS, 1997, p. 06). As infraestruturas são a materialização do trabalho humano sobre o território geográfico, na forma de caminhos, casas, plantações etc.

Estudar cada um desses fatores ou elementos isolados é uma abstração; porém, é analisando a relação que eles mantêm entre si que surge sua concretude e a real possibilidade de conhecer um determinado espaço. Cada um desses elementos detém 
significado próprio, dependendo do lugar em que estão. Duas variáveis iguais, mas em lugares diferentes, terão interações distintas com os outros elementos do espaço, adotando características e gerando resultados diversos para cada tópico. Portanto, o estudo do Centro como um espaço real compreende e se faz necessário a fim de aglutinar todos os elementos constitutivos dessa região (humanos e físicos) que atuaram em sua construção.

Uma derivação do conceito de espaço abordado neste trabalho é o espaço público definido, segundo Sola-Morales (2001), como aquele relativo ao domínio da administração pública de componentes do espaço geral da cidade e, em teoria, pertencente a todos: ruas, praças, parques, avenidas, calçadões etc. Esses espaços, em natureza, estariam em oposição aos espaços de domínio privado, propriedades particulares e com acesso restrito.

O conceito de Estado é entendido a partir de análises de Harvey (1978), feitas a partir de textos de Karl Marx, através da compreensão que a propriedade privada e os interesses particulares não estão subordinados a um pretenso interesse superior de um Estado absoluto; mas, sim, integrados a ele.

A sociedade civil é vista como a universalização das demandas do homem e, dentro de uma sociedade capitalista, as condições materiais seriam os elementos constituintes do nível de determinação dessa sociedade. Portanto, o Estado capitalista, ao abarcar o conteúdo social em sua conformação, passa a carregar os interesses diretos das classes dominantes, detentores das condições materiais. Esta conjuntura é produto da sociedade como resultado de um determinado momento histórico.

Com este contexto de fundamentação, o presente estudo compreende que as ações do Estado na cidade de São Paulo, tanto na esfera municipal, quanto estadual, representam a materialização dos interessas de camadas sociais com recursos suficientes para fazer suas vontades reverberarem dentro dos órgãos de poder, percebendo, dessa forma, os interesses por trás das diferentes propostas de intervenção estudadas, e compreendendo melhor os resultados objetivados para elas.

\section{A área de estudo e sua delimitação}

A demarcação do espaço do Centro, foco da análise deste trabalho, passa pelo esforço de conceituação deste espaço. Apesar de nos referirmos a um conjunto de avenidas, bairros, praças e ruas como pertencentes a esse local da cidade, o "Centro", esta concentração, na verdade, é uma abstração.

Há, no espaço compreendido como Centro, determinados territórios que podem ser mais facilmente delimitados, como: a região do Triângulo Histórico (TOLEDO, 1983), composta pela união do traçado viário cujos vértices são marcados pelos antigos conventos de São Francisco, do Carmo e Mosteiro de São Bento; a zona do Centro Histórico (TOLEDO, 1983; CORDEIRO, 1980), primeira ocupação da mancha urbana de São Paulo, contida entre os vales do Anhangabaú e Tamanduateí; e o Centro Novo (CORDEIRO, 1980), primeira vertente de expansão da cidade após o vencimento da barreira geográfica do Vale o Anhangabaú. 
Entretanto, a definição geral dos limites do Centro da cidade é nebulosa, posto que os distintos espaços, e os elementos compositivos desse lugar (o Centro), possuem suas peculiaridades. Mesmo considerando aspectos temporais, isto é, neste caso, todos os desenvolvimentos urbanos ocorridos até uma estipulada data, não seria possível determinar um fator de homogeneização entre os diferentes logradouros, que poderiam compor o espaço central de São Paulo.

Se tomarmos alguns pontos definidos por Santos (1997) para a composição estrutural de um determinado espaço - como estruturas demográficas, estruturas de renda, composição de classes, estruturas de produção -, chegaremos à conclusão de que bairros contíguos apresentam estrutura espacial díspar, configurando a existência de locais distintos.

objetivar dessa forma, objetivando definir a área central, foi utilizada a divisão espacial gerada pela Prefeitura Municipal de São Paulo, na qual o território do município é dividido em distritos, pertencentes ao território administrativo de Subprefeituras. Foram escolhidos os distritos da Sé e da República para compor a área de estudo deste trabalho, pois, conformando o que, nesta comunicação, é chamado de "Centro", compreendem tanto o núcleo histórico da cidade, quanto a presença dos equipamentos cuja escala, em importância, destacam-se no conjunto da organização municipal - principalmente equipamentos institucionais (LEFÈVRE, 1985).

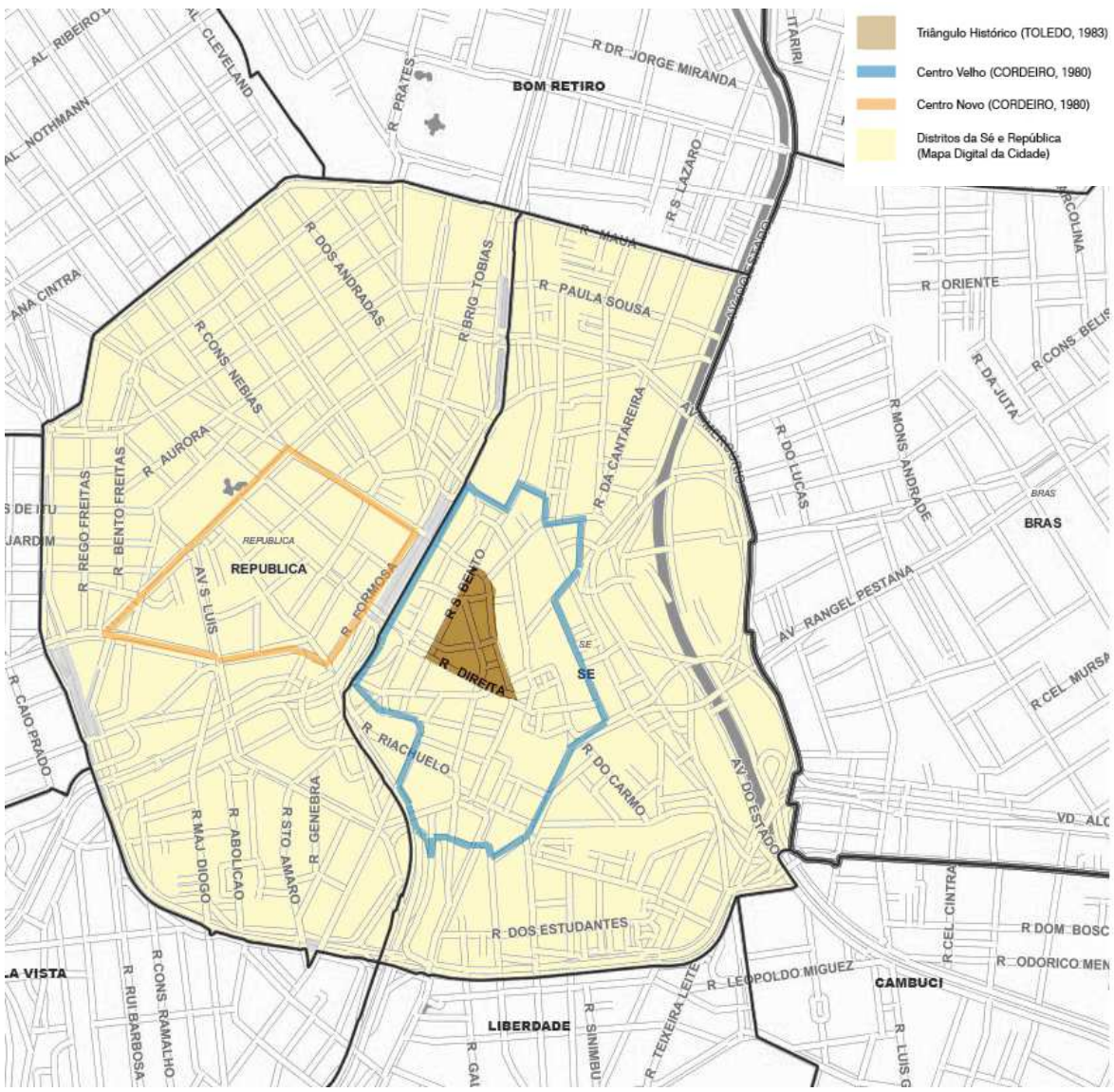

Figura 1: Delimitação da área de estudos. Fonte: Elaborada pelo autor com base do Mapa Digital da Cidade, 2020 


\section{O período de estudo - sua delimitação temporal}

Este estudo faz uso de um recorte histórico para alcançar seu objetivo de análise historiográfica. É construída uma linha do tempo para organização dos distintos projetos tomados para estudo, tendo como ponto de partida a chegada do transporte ferroviário na cidade de São Paulo, com a inauguração da estação da Luz e o início das operações da "The São Paulo Railway Company" em 1867 (TOLEDO, 1983). A periodização adotada buscou dividir o conjunto de anos compreendido nesta pesquisa em períodos distintos, buscando características comuns nos métodos de abordagem e das propostas em relação ao espaço público da cidade.

Essa periodização permite compreender melhor os personagens e mecanismos atuantes em comum em um período estabelecido, possibilitando, por sua vez, que as conclusões alcançadas com os trabalhos selecionados sejam extrapoladas para as relações gerais da atuação das administrações públicas em relação ao Centro.

A construção de uma linha do tempo torna-se ferramenta fundamental para a orientação deste trabalho, que se norteia pelos períodos históricos e pelas divisões temporais propostas para cada capítulo; permitindo também, a interconexão entre os projetos tomados como ponto de partida para a análise e diferentes personagens que estavam à frente da máquina estatal nos períodos correspondentes.

\section{O projeto do espaço público do centro de São Paulo}

O conjunto de espaços que conforma o Centro de São Paulo -avenidas, galerias, praças e ruas - é resultado de um longo processo de transformações, apagamentos e reconstruções, representantes de uma cidade "reconstruída duas vezes sobre si mesma, no último século" (TOLEDO, 1983, p. 67). O esforço movido para incentivar tais processos de mudanças não foi aleatório ou esporádico, mas, sim, fruto de iniciativas individuais e demandas coletivas por determinados grupos sociais.

A cidade colonial perdurou até meados do século XIX, com grande impulso de mudança gerado após a construção das linhas férreas cruzando a capital, escoando a produção de café vinda do interior até Santos, para posterior exportação. Contudo, como exposto por Taunay (2004), foi exatamente o trem que rompeu, derradeiramente, a barreira que era a Serra do Mar, integrando São Paulo aos fluxos de capital e ao pensamento desenvolvimentista burguês global.

Esse fenômeno fica claro quando Toledo (1983) analisa como as locomotivas não levavam apenas o café para o porto, mas também traziam novos materiais, novos conhecimentos e novas tendências de outras partes do globo:

O trem que desceu carregado de café pode, agora, sobe com material de construção para se fazer uma casa igual àquela vista em alguma capital europeia. É possível morar com desafogo e conforto na capital. Como na sede de fazenda, como na Europa (TOLEDO, 1983, p. 67) 


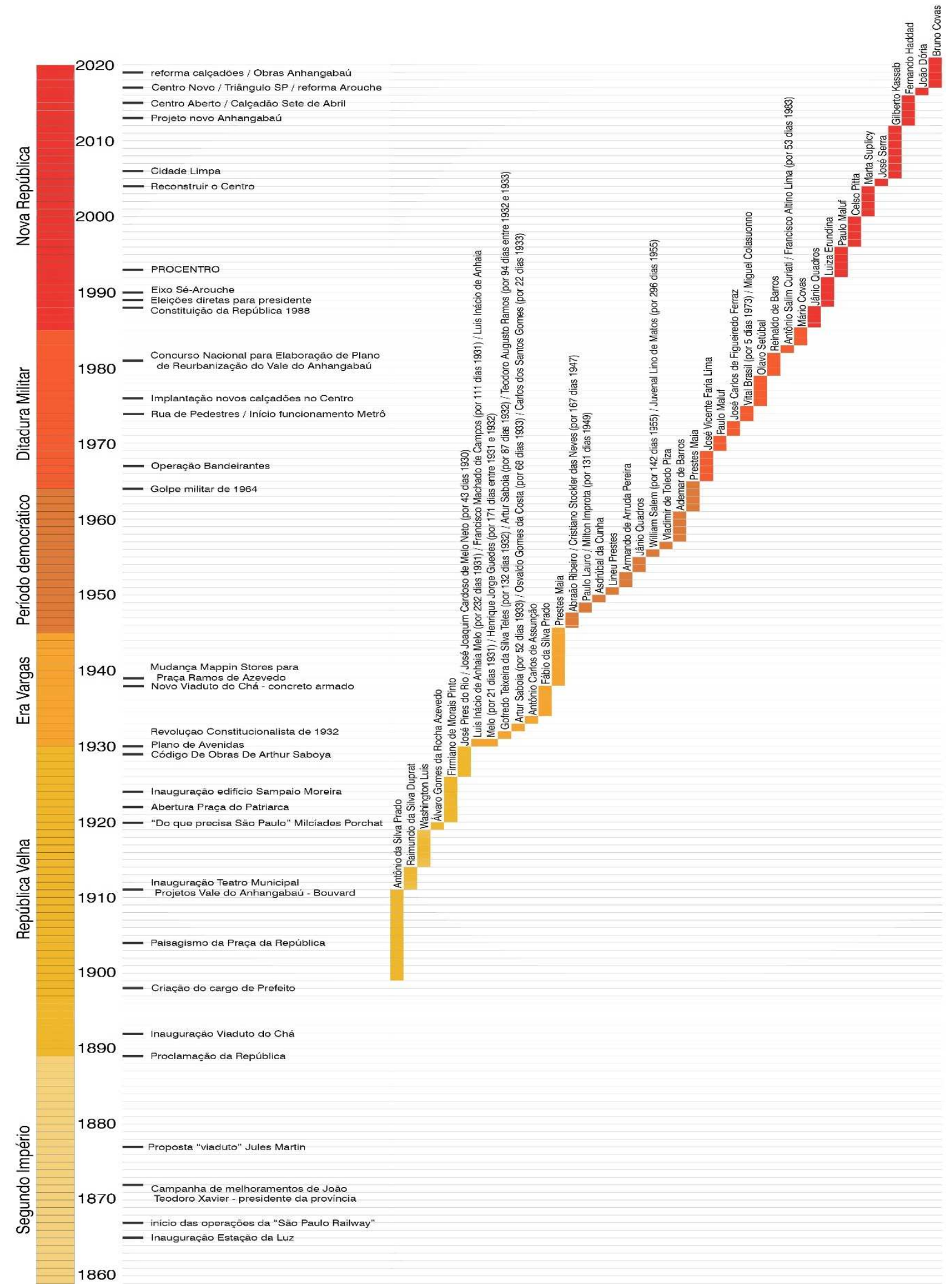

Quadro 1: O período de estudo, com as divisões temporais e projetos abordados na pesquisa. Fonte: Elaborado pelo autor, 2020. 
Apesar da chegada da ferrovia, não foi somente por ela que o impulso desenvolvimentista de São Paulo se iniciou. Personagens da administração pública da época, como o Dr. João Teodoro Xavier de Matos, perceberam a iminente necessidade de mudanças na capital, a fim de que pudesse haver desenvolvimento a partir da riqueza proveniente do café (CAMPOS apud HAIDAR, 2020).

Xavier de Matos, presidente da Província de São Paulo de 1872 até 1875, empeendeu melhoramentos que contaram com a reforma do Jardim da Luz (defronte do novo ponto de entrada da cidade que era a estação ferroviária), com a qual se construiu uma torre-observatório; abertura das ruas Conde d'Eu (atual Rua do Glicério), João Teodoro e da Palha (atual Sete de Abril); alargamento das ruas do Pari, do Gasômetro, do Hospício (atual Rua Frederico Alvarenga) e Municipal (atual Ladeira General Carneiro); e com a regularização do Largo dos Curros (atual Praça da República) (CAMPOS apud HAIDAR, 2020, p. 45-47).

Essas obras desenhavam um percurso viário, fazendo a conexão entre áreas em expansão na malha urbana e as estações de trem nos bairros da Luz e do Brás, e concebiam uma cidade capaz de atrair os capitais da província (CAMPOS, 2002), além de atrair a elite cafeeira, antes espalhada pelos interiores da província, iniciando, assim, a construção de residências e, consequentemente, investimentos na cidade.

A cultura cafeeira, como afirma Caio Prado Junior (1942 apud BRUNO, 1954), criou uma sociedade poderosamente agrícola, na qual imperava uma elite com suas origens traçadas no campo, indivíduos estes cuja referência de cidade se situava na Europa, com maior rigor em Paris. Foi essa visão e essa sociedade que guiaram as políticas públicas da administração municipal e estadual quanto ao desenvolvimento dessa crescente capital, em especial seu centro, no tocante ao planejamento de espaços públicos, obras de melhorias urbanas e equipamentos, a rigor até finais da década de 1920 .

Grandes campanhas de embelezamento foram empreendidas, todas almejando a modernização e "europeização" desse núcleo urbano (CAMPOS, 2002). Os espaços públicos foram alvo de intervenções; a Praça da República e o Largo do Arouche, por exemplo, adquiriram paisagismo. Também surgiram novas arquiteturas surgiram a fim de incrementar a cultura a moldes europeus para uma elite ávida, destacando o Teatro Municipal, inaugurado em 1911. Ainda, menciona-se a urbanização do Vale do Anhangabaú, com a demolição dos últimos resquícios de uma cidade, outrora acanhada e agrária, próximos ao Centro, com a instalação, enfim, do grande parque projetado por Joseph-Antoine Bouvard.

Durante a década de 1920, deu-se um breve período de transição no modo de se "fazer" a cidade, com a presença de novos indivíduos cada vez mais influentes nos processos de tomada de decisão, em especial com a emergência de uma classe de imigrantes enriquecida que almejava destaque social (BRUNO, 1954).

A industrialização tomava impulso na cidade e novas tipologias construtivas começavam a despontar no Centro, com o aparecimento dos primeiros edifícios altos (BORGES, 1999). Acompanhando os notórios avanços tecnológicos, surgiram as primeiras discussões acerca da necessidade da urbe se adaptar para melhor comportar esses avanços, notadamente no que diz respeito aos espaços destinados ao automóvel (CAMPOS, 2002). 
A partir dos anos 1930, percebeu-se, efetivamente, uma guinada nos rumos das políticas públicas das gestões municipais. As opiniões da sociedade podem ser encontradas em publicações como as de Milcíades de Luné Porchat (1920, apud CAMPOS, 2002, p. 229-233), preconizando as demandas por espaço para a crescente presença do automóvel no cotidiano da cidade.

A grande revolução veio a partir do "Plano de Avenidas" de Prestes Maia e Ulhôa Cintra, ao propor um plano não só para os espaços centrais, mas também para toda a área urbana, passando pela construção de todo um sistema radial de avenidas enfatizando o caráter de centralidade para a região, além de propor a remodelação de edifícios públicos e a padronização de critérios arquitetônicos para a nova cidade almejada.

A discussão acerca da região central de São Paulo propunha que esta passaria a ser a concentração de um amplo sistema radial de vias, conectando-o diretamente aos bairros limítrofes da área de expansão urbana, O sistema, a fim de firmar o espaço como centralidade, remodelaria sua arquitetura e imporia novos edifícios institucionais em pontos focais da planejada malha viária (MAIA, 1945). Contudo, essa reformulação espacial representou o rompimento com as obras de melhoria e embelezamento de administrações anteriores, com o apagamento de importantes obras empreendidas e completa transformação do Vale do Anhangabaú de parque público para avenida. As obras da gestão de Prestes Maia (1945) representam as últimas grandes iniciativas de remodelação espacial empreendidas no Centro, com abertura de novas vias e transformação dos espaços públicos.

A inauguração do novo Viaduto do Chá em 1938, já na gestão de Prestes Maia, marcou um primeiro movimento de migração da centralidade econômica para fora da colina histórica, rumando para o Centro Novo; fato marcado pela transição da sede da loja de departamentos Mapin, da Praça do Patriarca para um novo edifício na Praça Ramos de Azevedo (SIMÕES Jr., 2004). Esse movimento impulsionou o surgimento de novos espaços urbanos, de cunho privado, mas voltados para o uso público: as galerias comerciais (ALEIXO, 2005; FONTENELE, 2010).

As administrações municipais seguintes, até o fim dos anos de 1960, representaram, na sua maioria, uma migração do interesse público que acompanhou a paulatina saída das funções de centralidade econômica do Centro para outras regiões da cidade. As demandas do mercado imobiliário, por exemplo, motivaram investimentos públicos em infraestrutura em áreas mais afastadas, seguindo o vetor de desenvolvimento da cidade na direção sudoeste (SOMEKH, 2004 apud EMURB, 2004). Iniciou-se no Centro, então, um processo de substituição de usos e popularização da área, reflexo da saída de grandes empresas, o que ocasionou uma progressiva queda no número de moradores (FRÚGOLI, 2000). Porém, percebe-se que não se pode afirmar que houve um completo esvaziamento da região, pois ainda era importante polo de comércio varejista, local de trabalho e de passagem diária de grande população (EMURB, 2004), fatores estes que geraram problemáticas com a superlotação de veículos nas vias consideradas muito estreitas.

Projetos surgidos no fim dos anos de 1960, com maior fôlego na década de 1970, buscaram remediar as disputas por espaço entre os pedestres e o grande número de veículos que circulavam pelo Centro; estes responsáveis por tamanho grau de poluição ambiental e sonora que reverberava na cobertura midiática da questão. Surgiram experiências de restrição da circulação de automóveis em ruas dos centros Velho e 
Novo (LEFÈVRE, 1985), culminando no projeto de ampliação dos calçadões centrais durante a gestão de Olavo Setúbal. A similaridade destes projetos, além da temática, foi a maneira como propuseram suas intervenções, considerando o Centro como espaço urbano consolidado; atuando sobre a região a fim de buscar soluções de função (mudança do uso das vias privilegiando pedestres, por exemplo) e não soluções formais (abertura de novo viário, novas praças, etc.).

A partir de finais dos anos de 1980 e 1990 percebe-se que as administrações municipais desenvolvem planos de atuação mais abrangentes, abordando várias problemáticas, como encortiçamento, habitação social, patrimônio, etc.; ao mesmo tempo ocorrem parcerias com a sociedade atuando sobre questões pertinentes ao Centro, do mesmo modo que integrantes da sociedade civil se organizam em associações para que demandas ganhem maior representatividade ao serem abordadas junto ao poder público.

Caso notável é o da Associação Viva o Centro, união de proprietários do comércio e serviços, atuantes na região central e, à época de sua fundação, em 1991, encabeçados pelo BankBoston. Essa entidade marcou rumos das políticas públicas por mais de uma administração, com ênfase para a gestão Paulo Maluf com o surgimento do PROCENTRO (1993), programa para recuperação do Centro com grande destaque para a requalificação dos espaços públicos e restauro do patrimônio edificado, a fim de encorajar a atração de maior público para a área.

Constata-se, a partir das primeiras abordagens dos anos de 1990, com maior impulso a partir dos anos de 2000, a integração de projetos sociais no Centro com iniciativas para atração de visitantes, norteadas por uma percepção acerca do potencial turístico da região, entre as diferentes administrações. Os meios para se alcançar esse fim variaram, passando por investimentos em zeladoria, novos equipamentos culturais, legislações regulamentando publicidades, reforma de espaços públicos como calçadões e praças, implantação de novo mobiliário urbano, fomento de atividades e festivais artísticos etc.

A partir da década de 2000, identifica-se uma nova linha condutora comum nos projetos das diferentes administrações municipais quanto ao Centro. Apesar de o Procentro, lançado durante o governo de Paulo Maluf, ter gerado a atração de shows e outras atividades culturais para a região central (SIMÕES JUNIOR. 1994), foi a partir da a gestão de Marta Suplicy (2001-2004); que aliaram projetos sociais, de transportes e de habitação com a crescente busca pela atração da cultura para o Centro.

Ainda sobre essas ações, menciona-se, o projeto Centro Aberto, lançado pela gestão do prefeito Fernando Haddad (2013-2016), cujo objetivo era "'transformar" locais da cidade antes pouco atrativos, para a permanência da população, através de intervenções rápidas e instalação de mobiliário, muitas vezes móvel e temporário, para fomentar o uso da região alvo" (HAIDAR, 2020, p. 185). Juntamente com as instervenções em ogradouros públicos houve a construção de novos espaços culturais, a criação de festivais e programações diversas, além do desenho de intervenções no espaço público a fim de gestar palcos para realizações artísticas (Figura 2), entre outras iniciativas. É possível conceber que a gestão de Fernando Haddad almejava dar aos espaços públicos, selecionados para intervenção, mais do que apenas as características de um espaço de domínimo da administração pública, mas transformá-los em locais de uso e apropriação coletiva da população (SOLA-MORALES, 2001). 


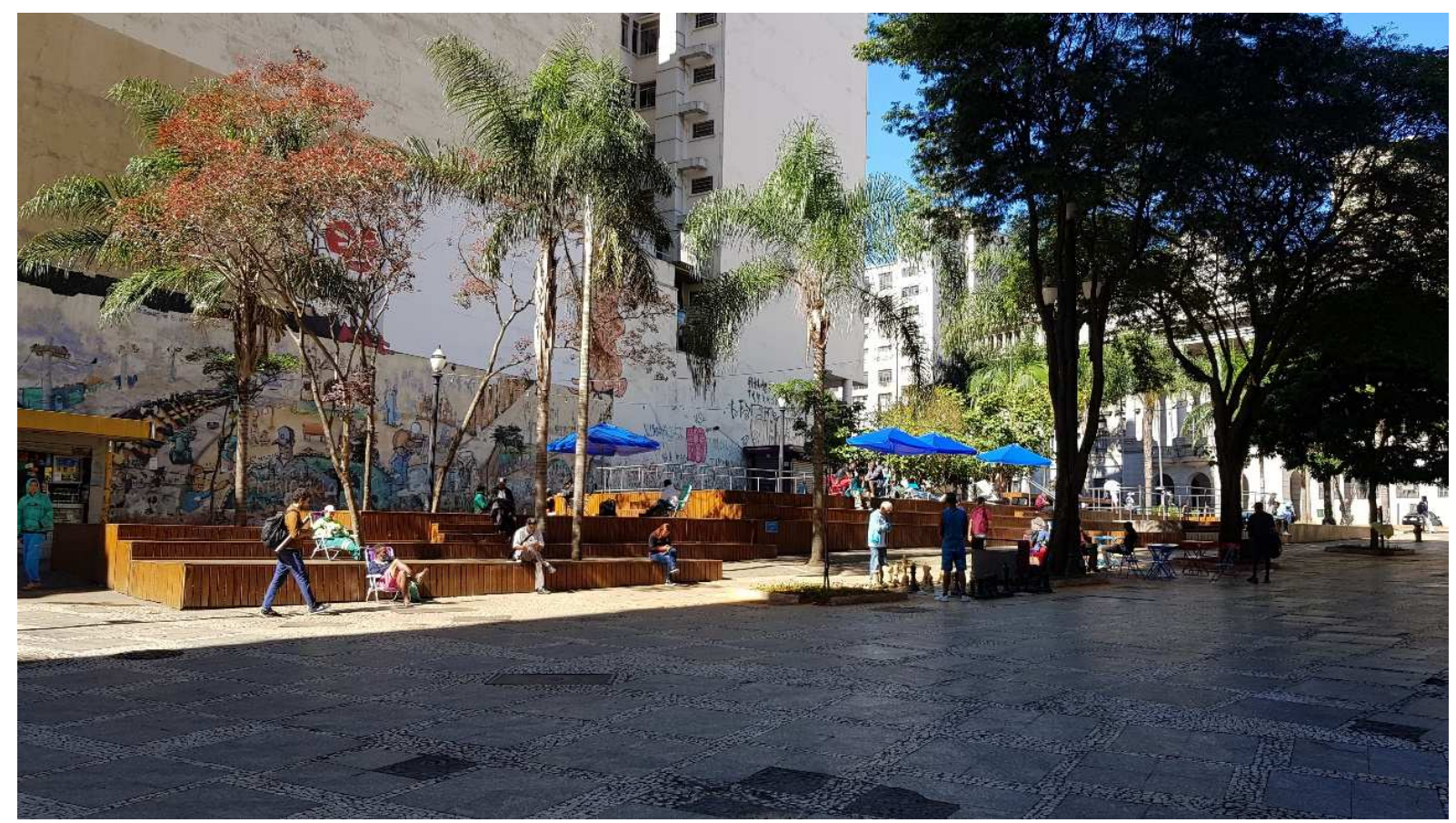

Figura 2: Praça Ouvidor Pacheco e Silva com manutenção no uso e permanência do mobiliário temporário e equipamentos de lazer. Fonte: Acervo do autor, 2019.

Fator comum e norteador, possível de se extrair dessas distintas intervenções, é a prática, por parte de diferentes administrações municipais, de delegar à cultura o poder de atração para novos visitantes, principalmente para além dos horários comerciais, a fim de amparar novos usos, sendo ela, ponto de partida para transformações mais amplas e introdução de novas atividades econômicas, como o turismo (HAIDAR, 2020).

Apesar da observância de tendência ao retorno do investimento particular no Centro, com incremento de novos lançamentos imobiliários e crescimento na permanência da população na área para além dos horários comerciais, em direção oposta, também se verificou a falta de continuidade de ações entre as diferentes administrações, em diversas iniciativas mais recentes. Esse fator gera duas consequências:

1) interrupção de projetos, que poderiam ampliar seu impacto ao longo de um período maior, ou o abandono de iniciativas que ainda se encontravam na esfera conceitual. Alguns exemplos que podem ser citados são as iniciativas da gestão municipal de Marta Suplicy, como os programas Investir no Centro, Caminhar no Centro, entre outros; ou os planos das gestões Serra/Kassab, em especial a Nova Luz, que, após longo percurso de planejamento, foi descontinuado na mudança de administração.

2) diretamente conectada à primeira, a busca por uma grande rapidez em alguns projetos e suas implantações ainda dentro de uma mesma gestão, criando consequências como a sua não completa finalização ou a baixa qualidade do resultado alcançado. Um exemplo recente é a reforma do Largo do Arouche entregue em 2020, porém sem aspectos cruciais da proposta inicial. 


\section{CONCLUSÃo}

No início desta pesquisa objetivou-se construir uma linha do tempo capaz de organizar mais de 150 anos abordados em momentos distintos, trazendo diversos enfoques da sociedade e do Estado em relação ao desenvolvimento do espaço público, organizando, assim, a construção da temporalidade que norteia estudo. Contudo, neste momento de conclusão, vale reestruturar a linha do tempo para construir um quadro sintético para se compreender as diferentes abordagens em relação ao Centro.

Foi feita a divisão temporal períodos mais amplos, unindo datas estudadas em diferentes capítulos para, desta forma, expor os pontos em comum entre os projetos analisados pertencentes às diferentes administrações municipais atuantes naqueles anos (Quadro 2).
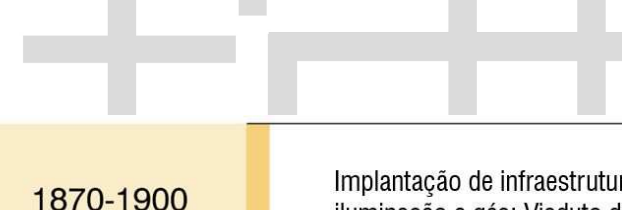

$1870-1900$ Implantação de infraestruturas básicas - pavimentação; bonde; iluminaçã̃o a gás; Viaduto do Chá; etc.

\begin{tabular}{cl}
\hline \multirow{2}{*}{$1900-1930$} & $\begin{array}{l}\text { Embelezamento / europeização - obras infraestruturais (Anhangabaú, } \\
\text { Várzea do Carmo) e estéticas; paisagismo de praças; etc. }\end{array}$ \\
\cline { 2 - 3 } 1930-1960 & $\begin{array}{l}\text { Abertura de avenidas; hegemonia do automóvel; embelezamento (mas } \\
\text { agora modelado em relação aos Estados Unidos da América). }\end{array}$ \\
\hline 1960-2000 & $\begin{array}{l}\text { Mudança da centralidade; questões geradas pelo automóvel (poluição, } \\
\text { trânsito, disputa por espaços, etc.); reabilitação do Centro. }\end{array}$ \\
\hline 2000-2020 & $\begin{array}{l}\text { Incentivar retorno do uso habitacional; poluição visual; reconhecimento } \\
\text { do uso popularizado; incremento atividades culturais. }\end{array}$ \\
\hline
\end{tabular}

Quadro 2: Quadro sintético das características em comum nas intervenções no Centro. Fonte: Elaborado pelo autor, 2020.

Portanto, de forma concisa, este trabalho constrói o percurso de criação dos espaços públicos centrais, tentando descrever como eles são oriundos de conformações de fatores e influências mutáveis através dos tempos, com diferentes prioridades e projetos de cidade.

Atualmente, a experiência que temos, ao percorrer o Centro, é resultado tanto das propostas que foram concretizadas, como das discussões, que nunca saíram do campo projetual, influenciando, contudo, as administrações púbicas e a sociedade civil; e como os interesses de grupos ou de indivíduos foram os responsáveis pela tomada de decisões e como as dinâmicas de formação desse Centro estão integradas a processos mais amplos de desenvolvimento local e regional. 
A análise do período proposto permite perceber as mudanças de foco do poder público e da sociedade em relação a esse espaço da cidade, o Centro. O século XX presenciou a mudança do público, que faz uso e frequenta essa região, havendo a migração da presença das elites paulistanas para uma maior popularização de funções. Algumas propostas mais recentes, a partir de finais do século XX e início do século XXI, reconhecem essas mudanças e desenvolvem propostas de acordo.

Contudo, este trabalho se encerra com alguns questionamentos: que Centro queremos? Para quem e para qual público queremos? Serão mantidas as leituras que pautam projetos que reconhecem os usos populares do Centro, ou haverá um retorno de tentativas de recuperação de um público que não usa mais a área? Tais questões se apresentam, principalmente, como motivadores para a continuação do estudo neste tema e neste local de São Paulo.

\section{REFERÊNCIAS}

ALEIXO, C. A. P. Edifícios e galerias comerciais: arquitetura e comércio na cidade de São Paulo, anos 50 e 60. 2005. Dissertação (Mestrado em Tecnologia do Ambiente Construído) - Universidade de São Paulo, campus São Carlos, São Carlos, 2005.

BORGES, E. F. São Paulo e a origem dos arranha-céus. São Paulo: RG Editores Ltda., 1999.

BRUNO, E. S. História e tradições da cidade de São Paulo. 2. ed. Rio de Janeiro: Editora José Olympio. 1954. v. III.

CAMPOS, C. M. Os rumos da cidade: urbanismo e modernização em São Paulo. São Paulo: Ed. Senac São Paulo, 2002.

CORDEIRO, H. K. O centro da metrópole paulistana: expansão recente. São Paulo: Edusp, 1980.

FONTENELE, S. Relações entre o traçado urbano e os edifícios modernos no centro de São Paulo. Arquitetura e Cidade (1938/1960). 2010. Tese (Doutorado em História e Fundamentos da Arquitetura e do Urbanismo) - Faculdade de Arquitetura e Urbanismo, Universidade de São Paulo, São Paulo, 2010.

FRÚGOLI Jr., H. Centralidade em São Paulo: trajetórias, conflitos e negociações na metrópole. São Paulo: Cortez, 2000.

HAIDAR, A. S. São Paulo Centro: 150 anos de projetos e realizações. 2020. Dissertação (Mestrado em Arquitetura e Urbanismo) - Universidade Presbiteriana Mackenzie, São Paulo, 2020. 
HARVEY, D. The Marxian theory of the state. Antipode, Baltimore, v. 8, n. 2, p. 80-89, maio 1978. Disponível em: https://onlinelibrary.wiley.com/doi/10.1111/j.14678330.1976.tb00641.x. Acesso em: 2 ago. 2020.

LEFÈVRE, J. E. de A. O papel do transporte coletivo como agente transformador da estruturação do centro da cidade de São Paulo. 1985. Dissertação (Mestrado em Arquitetura e Urbanismo) - Faculdade de Arquitetura e Urbanismo, Universidade de São Paulo, São Paulo, 1985.

MAIA, P. Os melhoramentos de São Paulo. Palestra pelo engenheiro Francisco Prestes Maia prefeito municipal. São Paulo: Prefeitura Municipal, 1945.

SANTOS, M. Espaço e método. 4. ed. São Paulo: Nobel, 1997.

SÃO PAULO (Município). Caminhos para o centro: estratégias de desenvolvimento para a região central de São Paulo. Empresa Municipal de Urbanização - EMURB. São Paulo: PMSP, 2004.

SIMÕES Jr., J. G. Revitalização de centros urbanos. Publicações Pólis. São Paulo: PÓLIS, 1994.

SOLA-MORALES, M. de. Espaços públicos, espaços coletivos. In: MEYER, R. M. P. (org.). Os centros das metrópoles: reflexões e propostas para a cidade democrática do século XXI. São Paulo: Associação Viva o Centro, 2001.

TAUNAY, A. de E. História da cidade de São Paulo. Brasília: Senado Federal. Secretaria Especial de Editoração e Publicação, 2004.

TOLEDO, B. L. de. São Paulo: três cidades em um século. 2. ed. São Paulo: Livraria Três Cidades, 1983. 